\title{
MANEJO DE RESÍDUOS SÓLIDOS E DE ÁGUAS PLUVIAIS: O (DES)CONTROLE SOCIAL EM BELÉM, PARÁ
}

\author{
SOLID WASTE AND RAINWATER MANAGEMENT: LACK OF SOCIAL CONTROL \\ IN BELÉM OF PARÁ
}

Daniel Alex Chagas Brito ${ }^{a}$, Larissa Cardoso Seabra ${ }^{a}$, Paola De Mello Limaa ${ }^{a}$ Cezarina Maria Nobre Souza ${ }^{a}$ Instituto Federal de Educação, Ciência e Tecnologia do Estado do Pará (IFPA)a

nielalex18@gmail.com, LarissaCardoso.lcs33@gmail.com, paolamello1996@gmail.com, cezarina.souza@ifpa.edu.br

\author{
Submissão: 30 de agosto de 2020 Aceitação: 10 de dezembro de 2020
}

\section{Resumo}

O estudo se propôs a caracterizar quantitativa e qualitativamente a atuação dos conselhos gestores de políticas públicas ligadas ao saneamento, no que tange ao manejo de resíduos sólidos e de águas pluviais, no município de Belém. Foram contatados 16 conselhos, com o fim de obter atas e resoluções que abordassem os temas de interesse, objetivando identificar: 1) quais conselhos, no âmbito da relação do saneamento com a saúde, o ambiente e o desenvolvimento urbano, têm pautas relacionadas aos dois temas em estudo; 2) quais conteúdos específicos são tratados nessas pautas; e 3) as consequências dessas pautas quanto à produção de Resoluções, Moções, etc. que formalizem e materializem a atuação dos conselhos que as produziram. Após a leitura crítica das atas e resoluções, os resultados obtidos revelaram que nenhum conselho contatado controla o serviço de manejo de águas pluviais em Belém, uma vez que este tema não foi tratado em nenhuma das atas consultadas dos conselhos participantes do estudo. O controle sobre o serviço de manejo de resíduos sólidos somente foi exercido em uma única abordagem por um conselho estadual, uma vez que os conselhos municipais contatados permaneceram ausentes dessa discussão.

Palavras-chave: Resíduos Sólidos; Águas Pluviais; Controle Social; Conselhos gestores de políticas públicas.

\section{Abstract}

The study aimed to characterize quantitatively and qualitatively the performance of public policy management councils related to sanitation, with regard to the management of solid waste and the management of rainwater, in the municipality of Belém. 16 councils were contacted in order to obtain minutes and resolutions that addresses the topics of interest to: 1) identify which councils, within the scope of the relationship between sanitation and health, the environment and urban development, have guidelines related to the two themes under study; 2) identify which specific contents are covered in these guidelines; 3 ) to identify the consequences of these guidelines regarding the production of Resolutions, Motions, etc., that formalize and materialize the performance of the councils that produced them. After a critical reading of the minutes and resolutions, the results obtained reveal that no council contacted controls the rainwater management service in Belém, since this topic was not addressed in any of the consulted minutes of the three municipal councils participating in the study. The control over the solid waste management service was only exercised in a single approach and by a state council, since the municipal councils contacted remained absent from this discussion.

Keywords: Solid Waste; Rainwater; Social Control; Public Policy Management Councils. 


\section{INTRODUÇÃO}

Belém, capital do Estado do Pará, é um município que convive com graves e antigos problemas ligados ao manejo dos resíduos sólidos que gera (FREIRE, 2010; OLIVEIRA, 2012). Mesmo iniciativas mais recentes, que se propunham a solucioná-los, redundaram em novos problemas (VASCONCELOS JUNIOR; CORRÊA, 2017; SOARES; QUEIROZ; SANTOS, 2018), pois o município, conurbado que está com os municípios de Ananindeua e Marituba, buscou, sem sucesso, desenvolver solução conjunta para tratamento e disposição final desses resíduos, por meio da implantação de um aterro sanitário, em Marituba.

Além disso, a cidade sofre com inundações urbanas (BRAGA; BARBOSA; ALMEIDA, 2014; PONTE, 2015), por conta da ocupação irregular de áreas ribeirinhas e da falta de manutenção nas estruturas do sistema de drenagem (PONTE; LEÃO; BARROS; CUTRIM, 2014; FRAGOSO; SILVA; SILVA; ALVES; CARVALHO, 2016; CAVALCANTE; MAGALHÃES; GOMES; CARVALHO, 2017), assim como em função da disposição inadequada dos resíduos sólidos nesse sistema (COSTA; BITTENCOURT; TEIXEIRA; BLANCO, 2016).

De acordo com a legislação nacional, todos os serviços de saneamento, o que inclui o manejo de resíduos sólidos e o de águas pluviais, devem ser prestados tendo em vista o princípio do controle social, definido como sendo o "conjunto de mecanismos e procedimentos que garantem à sociedade informações, representações técnicas e participações nos processos de formulação de políticas, de planejamento e de avaliação relacionados aos serviços públicos de saneamento básico (BRASIL, 2007).

Contudo, em Belém, há um Conselho Municipal de Saneamento que exerce controle social somente no campo do abastecimento de água e do esgotamento sanitário, deixando de envolver-se no que diz respeito aos serviços ligados aos resíduos sólidos e às águas pluviais. Sendo assim, vêm à tona as perguntas: Quem controla estes serviços, então? Que conselho desenvolveria ações que influenciem a política pública nesses campos?

A partir destas questões, propõe-se, como objetivo geral, caracterizar quantitativa e qualitativamente a atuação dos conselhos de controle social situados na interface do saneamento com as políticas correlatas, com vistas a verificar sua possível atividade no controle do manejo de resíduos sólidos e de águas pluviais, no município de Belém. Este objetivo, pelos motivos esclarecidos na seção seguinte, no que concerne ao manejo de resíduos sólidos, foi ampliado quanto à área de estudo, que passou a incluir os municípios de Ananindeua e Marituba.

Como objetivos específicos, propõem-se identificar: 1) quais conselhos, no âmbito da relação do saneamento com a saúde, o ambiente e o desenvolvimento urbano, têm pautas relacionadas aos dois temas em estudo; 2) quais conteúdos específicos são tratados nessas pautas; e 3) as consequências dessas pautas quanto à produção de Resoluções, Moções, etc., que formalizem e materializem a atuação dos conselhos que as produziram.

$\mathrm{Na}$ seção seguinte, é apresentada uma revisão da literatura sobre os temas centrais deste estudo. Na sequência, estão a metodologia empregada, os resultados obtidos e sua discussão, e, finalizando, apresenta-se a conclusão.

\section{DISPOSIÇÃO DOS RESÍDUOS SÓLIDOS EM BELÉM}

Belém atingiu 0 processo massivo de urbanização no início do Século $X X$, período da Belle-Époque, que trazia as características de produção, modernidade, industrialização e urbanização, fatores favorecedores do aumento exacerbado de resíduos sólidos, diante do crescimento populacional (DIAS; SILVA; SILVA, 2014).

Em 1901, o Intendente Antônio Lemos, dando curso a seu projeto de transformar a cidade em uma Paris n'América, instalou a Uzina da Cremação de Lixo de Belém (Figura 1). O empreendimento foi criado com 0 intuito de mitigar os problemas enfrentados pela população daquela época, dentre eles, a falta de higiene pública (havia monturos de resíduos nas ruas e mau cheiro) e de tratamento de resíduos sólidos (O LIBERAL, 2019).

O projeto foi desenvolvido em espaço que se distanciava do centro urbano. Contudo, o crescimento da cidade desencadeou a aproximação da massa populacional em torno do crematório, dando origem ao bairro da Cremação 
(SOARES, 2008). Ao longo do tempo, considerando falhas de operação e de manutenção, a Uzina se tornou responsável por intenso processo de poluição do ar, decorrente da fumaça e dos maus odores, e de poluição sonora, em função do ruído produzido pelos fornos crematórios, levando a população a se impor contra ela. Assim, na década de 1980, foi desativada, dando lugar à Praça Dalcídio Jurandir, que manteve, no entanto, a chaminé do forno, na tentativa de preservação da história $(0$ LIBERAL, 2019) (Figura 2).

Figura 1: Uzina de Cremação

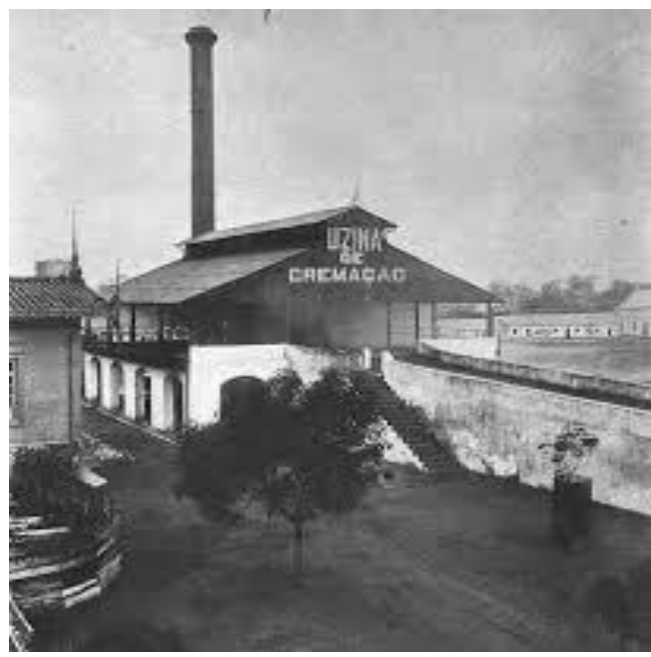

Fonte: O Liberal (2020).

Figura 2: Praça Dalcídio Jurandir

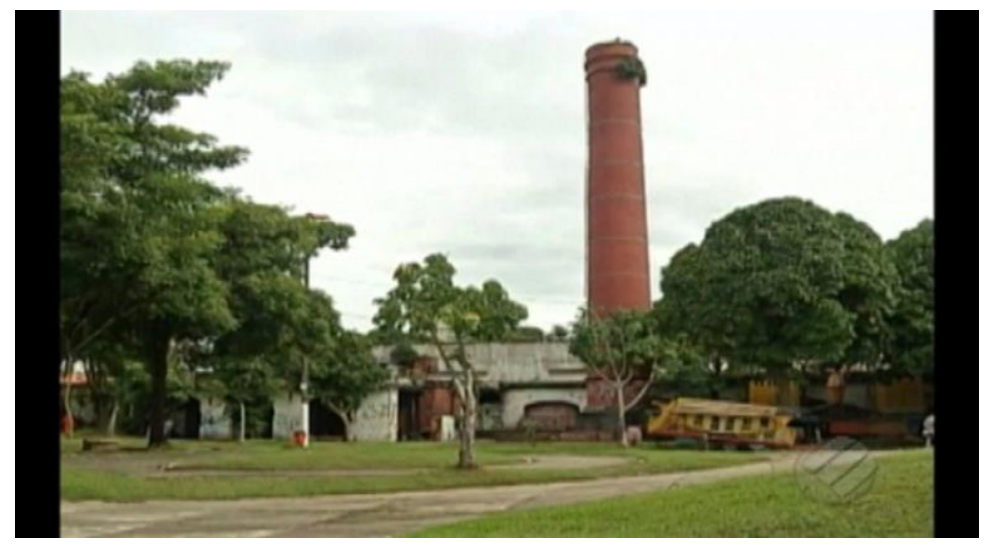

Fonte: $\quad$ https://www.oliberal.com/crema\%C3\%A7\%C3\%A3o-dequando-se-buscava-solu\%C3\%A7\%C3\%B5es-para-o-lixo-1.53618.

Após o fechamento da Uzina, desde 1987 (MATOS; MOURA; CONDE; MORALES; BRASIL, 2011), os resíduos sólidos passaram a ser dispostos em uma área adjacente ao rio Aurá (tributário do rio Guamá), próxima aos lagos Água Preta e Bolonha (mananciais de Belém localizados no Parque Estadual do Utinga), no bairro de Águas Lindas, periferia do município de Ananindeua (Figura 3).

Em 1991, foi proposto o projeto de implantação do Complexo do Aterro Sanitário do Aurá, que compreenderia uma usina de incineração de resíduos hospitalares, uma usina de compostagem e reciclagem, um aterro sanitário e duas lagoas de estabilização (FREIRE, 2010). No entanto, nos anos que se seguiram, esse projeto foi iniciado, mas nunca concluído, alcançando-se, por algum tempo, apenas a condição de aterro controlado, quando da adoção de técnicas adequadas de engenharia para 
controle dos líquidos e gases produzidos na decomposição orgânica, porém, sem a impermeabilização do solo (FREIRE, 2010).

Após quase 30 anos de atividade, recebendo por dia quase duas mil toneladas de resíduos de Belém e Ananindeua, como também dos municípios de Marituba, Benevides e Santa Bárbara, os quais integram a Região Metropolitana de Belém (RMB) (VASCONCELOS JUNIOR; CORRÊA, 2017), o Lixão do Aurá foi desativado em 2015, por apresentar: forte odor causado pela decomposição de alimentos e de animais; grande quantidade de moscas; vias esburacadas e sem sistema de drenagem pluvial; caminhões e caçambas despejando irregularmente todo tipo de resíduo (Figura 4); e contaminação da água pertencente ao Parque Ambiental Estadual do Utinga (LOBATO; TAVARES, 2012).

\section{Figura 3: Localização do Lixão do Aurá}

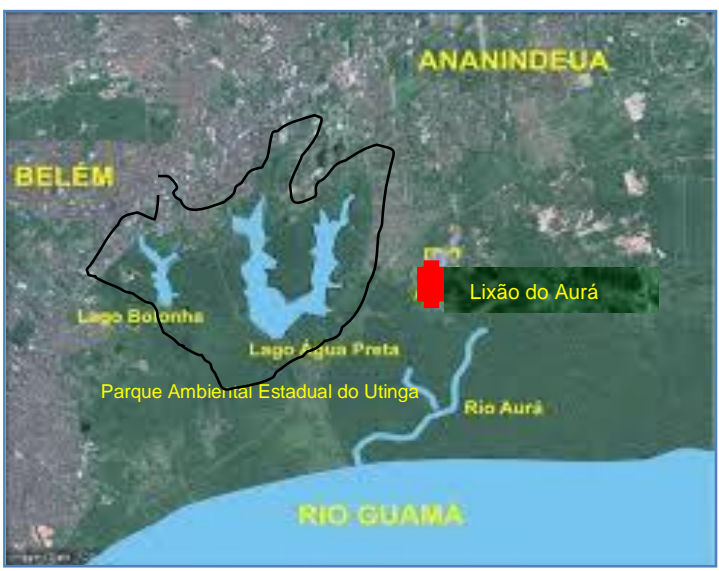

Fonte: https://www.google.com.br/search?q=lix\%C3\%A30+do+aur\%C3\%A1+parque+utinga\&sxsrf $=$ ALeKk02pmK4jxZqK_hbH84R8x00cEe5dQ:1608033102611\&source=Inms\&tbm=isch\&sa=X\&ved =2ahUKEwjwwPiO9s_tAhV9ILkGHSbdD3gQ_AUoAXoECAQQAw\&biw=1280\&bih=553\#imgrc=w7g fGXE5uygXsM

Figura 4: Descarga de resíduos no Lixão do Aurá e catadores em atividade

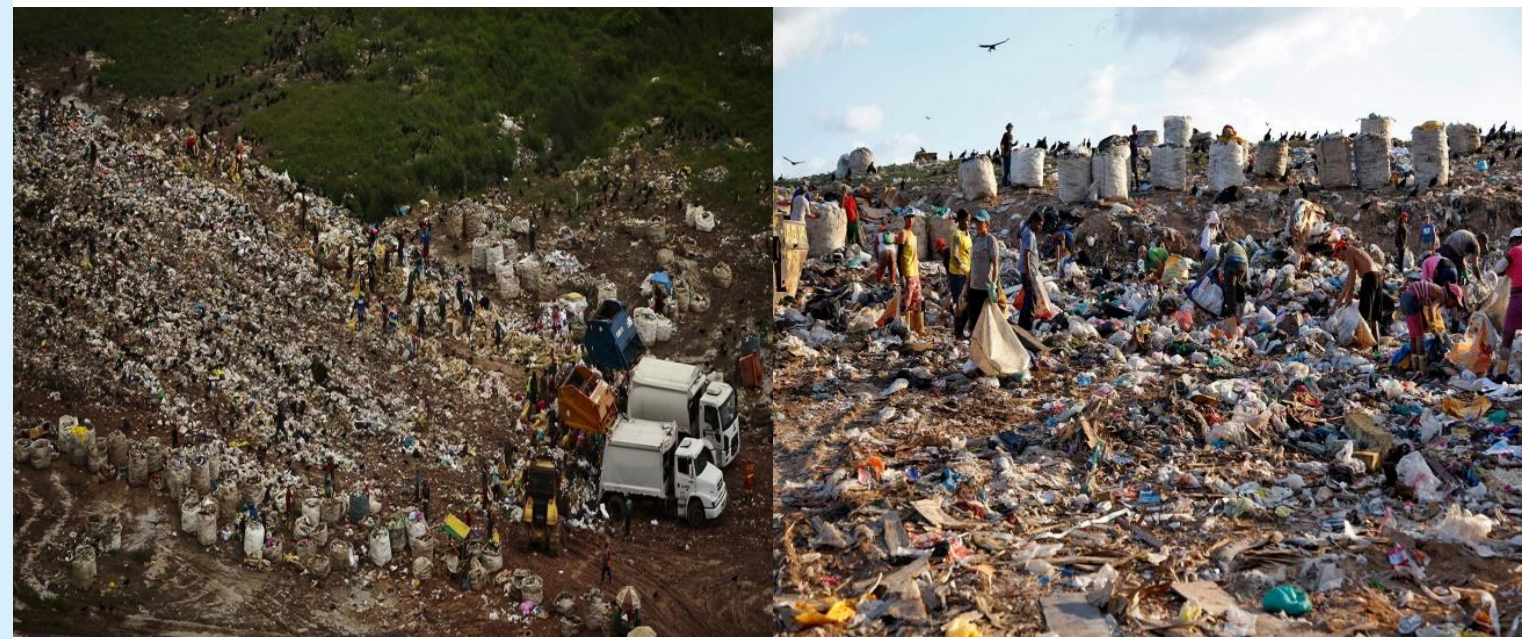

Fontes: https://www.jornaldotrem.com.br/vista-geral-do-lixao-do-aura/; http://adrielsonfurtado.blogspot.com/2014/03/lixao-do-aura-fim-do-segundo-maior.html

Antes da desativação do Lixão, os seis municípios componentes da RMB na ocasião (Belém, Ananindeua, Marituba, Benevides, Santa Bárbara do Pará e Santa Izabel do Pará), em evento público denominado Soluções Sustentáveis para os Resíduos Sólidos da Região Metropolitana, realizado em novembro de 2011, do qual participaram os gestores municipais da 
RMB e profissionais da área, buscaram associarse, entre si, por meio de um consórcio público. Este traria para si a responsabilidade de realização de licitação pública, para contratação de empresa privada que deveria assumir o gerenciamento dos serviços de disposição dos resíduos sólidos gerados nesses municípios (COSTA; MOREIRA, 2018).

No entanto, com a desativação do Lixão, em resposta às reivindicações da população local, impactada pelo não tratamento dos resíduos, e considerando a obrigatoriedade de adequação ao estabelecido pela Política Nacional de Resíduos Sólidos (PNRS), que proíbe a existência de lixões em todo o território nacional, a partir de junho de 2015, os resíduos de Belém, Ananindeua e Marituba passaram a ser dispostos no aterro sanitário privado, existente na Central de Processamento e Tratamento de Resíduos (CPTR). Esta Central localiza-se em Marituba, em área de 110 hectares (Figura 5) e de propriedade da empresa Revita Engenharia S.A, com sede no Estado de São Paulo, gerida pela Guamá Tratamento de Resíduos Ltda, ambas integrantes do Grupo Solvi Participações S/A (VASCONCELOS JUNIOR; CORRÊA, 2017).

Figura 5: Localização da CPTR, em Marituba

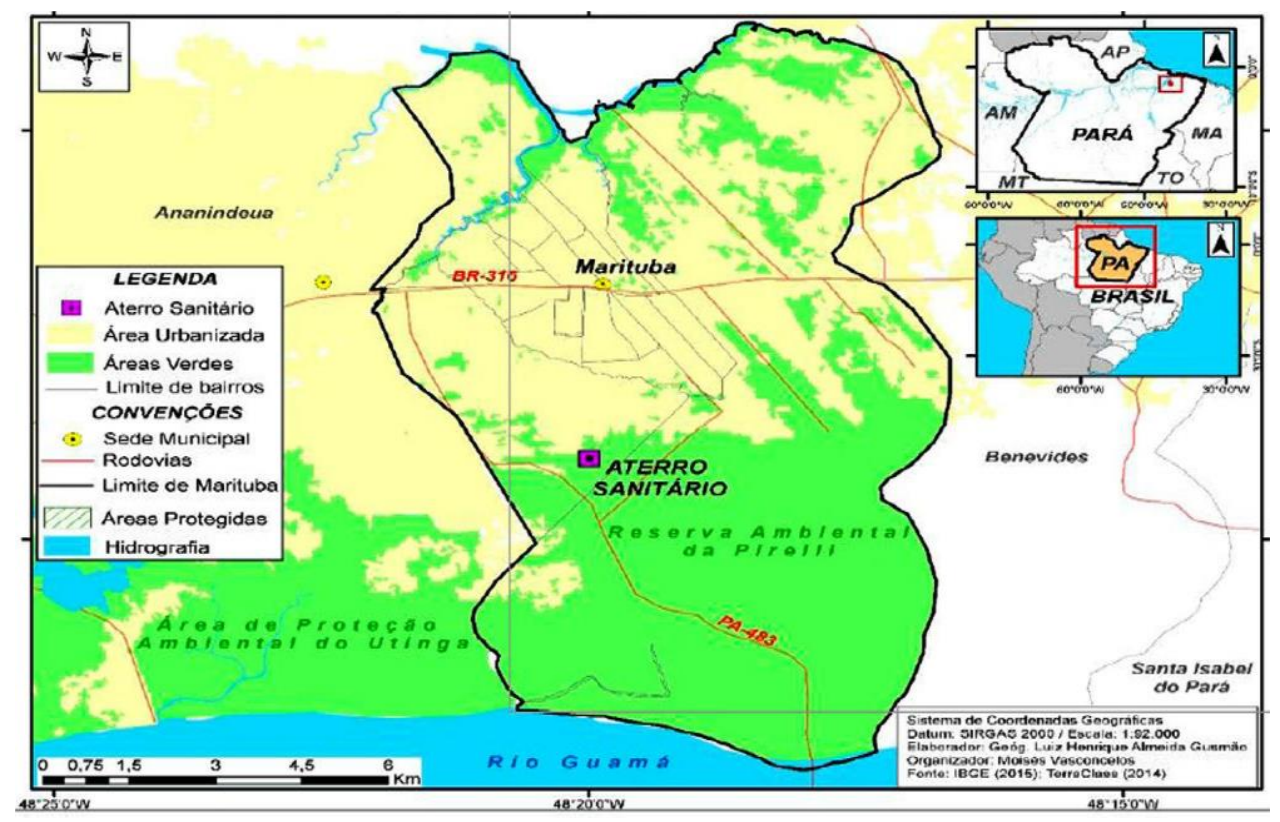

Fonte: Vasconcelos Junior; Corrêa (2017).

Nesse processo, a CPTR foi objeto de um Estudo de Impacto Ambiental (EIA), o qual foi examinado pelo Ministério Público do Estado do Pará (MPPA), tendo seu correspondente Relatório de Impacto Ambiental (RIMA) sido disponibilizado para acesso público em audiências públicas. Nessas audiências, foram identificadas deficiências, refutadas pela Revita, no que tange à área escolhida para implantação do empreendimento, quais sejam (COSTA; MOREIRA, 2018):

- já era antropizada (utilizada para extração de materiais para construção, em acentuado estado de degradação);

- é próxima a uma unidade de conservação ambiental de proteção integral;

- é densamente povoada;

- está situada na Área de Segurança
Aeroportuária (ASA), do Aeroporto Internacional de Belém (Val-de-Cans), do Aeroporto de Belém (Brigadeiro Protásio de Oliveira) e da Base Aérea de Belém; e

- não foi observada a faixa de $3 \mathrm{Km}$ determinada como distância mínima de segurança da área urbana.

A Prefeitura Municipal de Marituba, por meio de sua Procuradoria Geral, em agosto de 2011, concedeu a certidão de anuência à implantação do empreendimento, o que possibilitou a liberação da Licença Prévia por parte do Conselho Estadual do Meio Ambiente (COEMA), também fundamentado em pareceres emitidos pela Secretaria de Estado de Meio Ambiente e Sustentabilidade (SEMAS), órgão responsável pelo licenciamento ambiental no 
Pará. Na sequência, foram obtidas a Licença de Instalação e a Licença de Operação (COSTA; MOREIRA, 2018).

O projeto da CPTR, tal como foi proposto, contemplava (COSTA; MOREIRA, 2018):

- um aterro sanitário para destinação dos resíduos sólidos classe II (matéria orgânica, vidro, metais, papel) e seus sistemas de controle ambiental (para drenagem pluvial, tratamento de percolados e de biogás; para impermeabilização da base do aterro; para bombeamento de percolados);

- uma usina de triagem e compostagem; e

- uma usina termelétrica para geração de energia elétrica a partir do biogás.

Contudo, após o início de seu funcionamento, foram identificadas inúmeras falhas em suas instalações, gerenciamento e operação, que não condiziam com o projeto licenciado, o que levou a SEMAS a emitir diversas e sucessivas notificações contendo exigências, tais como (COSTA; MOREIRA, 2018):

- recobrimento dos resíduos contidos nas células em solo;

- cobertura de lagoa de estabilização por conta das chuvas;

- adequação do sistema de drenagem pluviométrica provisória, com execução de canalização seguindo a declividade do terreno;

- utilização de falcão robô para afugentamento de aves, não podendo ser implementado qualquer artifício pirotécnico para tal finalidade; e

- implantação de monitoramento diário de odor, na sede do município de Marituba, e com ponto de referência no município de Ananindeua, considerando a direção e intensidade dos ventos.

O desatendimento das exigências transformou a CPTR proposta em um lixão a céu aberto, responsável pelo desastre ambiental que levou à decretação, pelas autoridades, em 2017, de estado de emergência (VASCONCELOS JUNIOR; CORRÊA, 2017). Foram consideradas, para a tomada de tal decisão, a poluição do ar por conta da emissão de odores putrefatos, a poluição dos rios em decorrência do extravasamento das lagoas pelo acúmulo de água de chuva e do assoreamento dos rios por sedimentos, poluição do solo não impermeabilizado pelo lançamento de chorume, e poluição sonora pelo o uso de fogos de artifício para afugentar aves, uma vez que o falcão robô não atuava com eficiência.

Além disso, a população local que, desde 2011, já se manifestava contrariamente ao empreendimento, mobilizando-se em protestos (Figura 6), passou a sofrer impactos diversos, tal como revela o depoimento abaixo, concedido a Costa e Moreira (2018):

praticamente quase todos ali, em termos principalmente de saúde, questão econômica, o bem-estar da população, 0 ar, perdemos a qualidade do ar, totalmente poluído, um odor muito forte, a água com contaminação, o povo com receio de beber água, tanto é, que houve o estado de emergência que a população teve que receber água potável (COSTA; MOREIRA, 2018, p. 64).

Este conjunto de fatos fez com que os prefeitos de Belém, Ananindeua e Marituba assinassem Termo de Ajuste de Conduta, celebrado com o MPPA (G1-PARÁ, 2020a). Em abril de 2017, a pedido do governo do Estado, a Justiça determinou que este assumisse a cogestão da CPTR, a ser exercida por um colegiado composto por três técnicos (PARÁ, 2017).

Em julho de 2019, após três dias de audiências, totalizando 24 horas de discussões, um acordo celebrado entre as prefeituras, o Governo Estadual e o MPPA definiu os termos de como a CPTR deverá ser regulada e operada pelos próximos dois anos pela empresa Guamá Tratamento de Resíduos Ltda. Além disso, foi definido que, nesse ínterim, deverá ser encontrado local adequado para a implantação de uma solução definitiva para a disposição dos resíduos (PARÁ, 2019).

\section{INUNDAÇÕES URBANAS EM BELÉM}

Inundações e alagamentos são fenômenos diferenciados das enchentes dos rios. Enquanto estas são naturais, ocorrem com frequência variável e, muitas vezes, inesperada, as inundações decorrem da ocupação indevida e variada de áreas que pertencem ao leito maior dos rios, muitas vezes durante largos períodos em que não há enchentes, caracterizando 
desrespeito aos ciclos dos ambientes aquáticos (BRASIL, 2019). Por sua vez, os alagamentos são caracterizados pelo acúmulo temporário de água que, por alguma deficiência do sistema de drenagem, não pode escoar (SOUSA, 2016).

No caso de Belém, constituem o fator primordial para a ocorrência de enchentes as suas características físicas naturais, tais como, a hidrografia, a topografia e a pluviometria (SADECK, 2011). A cidade é recortada por cursos d'água, configurando 14 bacias hidrográficas
(BELÉM, 2020). Grande parte de seu território encontra-se em cotas altimétricas iguais ou inferiores a quatro metros, denominadas baixadas. Estas são áreas sujeitas às condições de maré, relativamente adensadas, atingindo as densidades mais altas de toda a RMB, em torno de 300 hab/ha (PINHEIRO; PONTE; VALENTE; LIMA; PINHEIRO, 2016), onde vive, assentada de forma precária, parte da população de baixo poder aquisitivo (Figura 7) (SANTOS; ROCHA, 2013).

Figura 6: Protestos ocorridos contra a CPTR, em Marituba

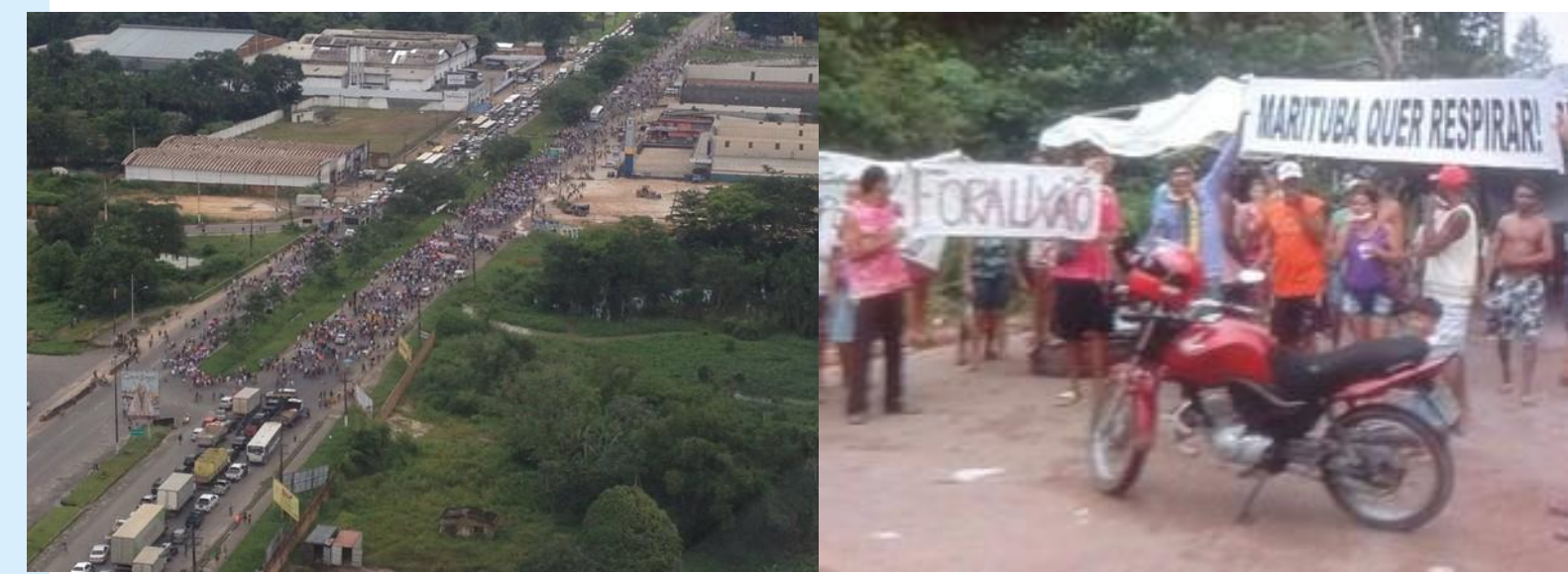

Fontes:

https://www.google.com.br/search?q=fora+lix\%C3\%A30+marituba\&tbm=isch\&sxsrf=ALeKk02TknzL42RT84ZXve6x7DQmU298dQ: $1608033508277 \&$ source $=$ Inms\&sa=X\&ved=0ahUKEwiGqLDQ98 tAhX EbkGHYA8C9gQ AUIESgD\&biw=1280\&bih=553\&dpr=1.5\# imgrc=qkN6Ks\|BrwesM

https://www.google.com.br/search?q=marituba+quer+respirar\&tbm=isch\&ved=2ahUKEwjE-

5fT98 tAhWRBLkGHe CBVUQ2cCegQIABAA\&oq=marituba+quer+respirar\&gs Icp=CgNpbWcQAzoECAAQQzoCCAA6BAgAEBh Q4uwJWMCUCmCfpQpoAnAAeACAAfYBiAH1FpIBBjAuMTUuMZgBAKABAaoBC2d3cy13aXotaW1nwAEB\&sclient=img\&ei=6qTYX 8TeCZGJ5OUP74WXqAU\&bih=553\&biw=1280\#imgrc=93Zc4X0lade-ZM

\section{Figura 7: Palafitas}

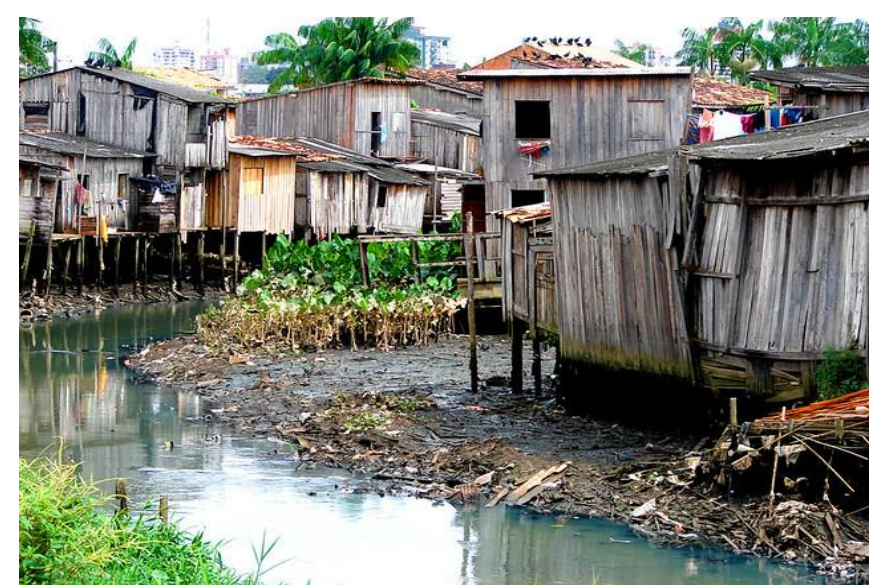

Fonte: https://www.google.com.br/search?q=palafitas+em+belem\&tbm=isch\&ved=2ahUKEwj42aOk-

M tAhWLL7kGHQ4cANcQ2-cCegQIABAA\&oq=palafitas+em+belem\&gs $I c p=$

CgNpbWcQAzICCAA6CAgAELEDEIMBOgUIABCXAzoECCMQJzoECAAQQzoECAAQGFDfpRhYpboYYN68GGgAcAB4

AYABoAKIAe4XkgEGMC4xNy4xmAEAoAEBggELZ3dzLXdpei1pbWfAAQE\&sclient=img\&ei=IKXYX i DYvf5OUPjiAuA0

\&bih=553\&biw=1280\#imgrc=PjLlbELHPWel M 
O clima local, influenciado pela floresta amazônica, por seus rios e pela proximidade com o oceano Atlântico, é caracterizado por duas estações: a chuvosa, de dezembro a maio, e a menos chuvosa, de junho a novembro. Em geral, os maiores índices pluviométricos são medidos entre os meses de janeiro a abril, observando-se os maiores valores em março (438 mm/mês). O período de menor precipitação ocorre entre agosto (127 mm/mês) e novembro (111 mm/mês) (MORAES; MANOEL FILHO, 2018).

De maneira geral, e em Belém não é diferente, 0 processo de alagamentos e inundações, responsável por colocar grande parte da população sob risco ambiental, social e patrimonial, inclusive em áreas não periféricas da cidade (FRAGOSO; SILVA; SILVA; ALVES; CARVALHO, 2016), deve-se à ineficiência e ao sucateamento do sistema de drenagem pluvial (BRAGA; BARBOSA; ALMEIDA, 2014), bem como ao depósito de resíduos sólidos nas proximidades dos cursos d'agua, ou mesmo diretamente dentro deles (Figura 8). Deve-se, ainda, a fatores como 0 assoreamento, a retificação e 0 aterramento dos cursos d'agua, promovidos pelas políticas públicas, desde 0 início do século XIX (SADECK, 2011; CRUZ, 2018).

\section{Figura 8: Sucateamento do sistema de microdrenagem e disposição de resíduos sólidos nas} margens de canal

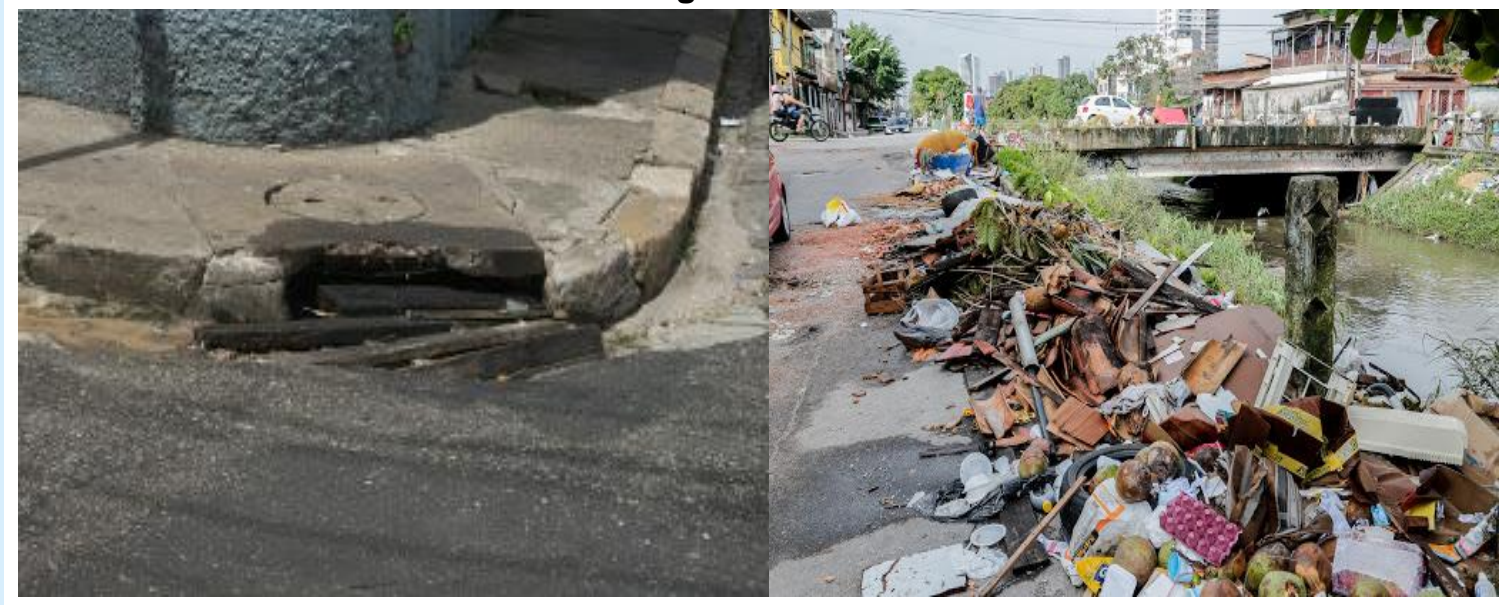

Fontes: https://www.google.com.br/search?q=belem+melhor+drenagem+pluvial +boca+lobo\&tbm

=isch\&ved=2ahUKEwj7nKXe-8 tAhW-M7kGHdxvBiUQ2-cCegQIABAA\&oq=belem+melhor+drenagem

+pluvial+boca+lobo\&gs Icp=CgNpbWcQA1Dw6QZYz oGYPaDB2gAcAB4AIABtQKIAYIPkgEHMC44LjEuMZgBAKABAa oBC2d3cy13aXotaW1nwAEB\&sclient=img\&ei=M6nYX7u3C77n5OUP3N-ZqAl\&bih=553\&biw=1280\#imgrc=RTagQPXHSLKQM

https://www.google.com.br/search?q=ag\%C3\%AAncia+belem+lixo+canal\&tbm=isch\&ved=2ahUKEwiDpfiV M tAhXvNLk GHb1qBccQ2-cCegQIABAA\&oq=ag\%C3\%AAncia+belem+lixo+

canal\&gs Icp=CgNpbWcQAzoECCMQJzoFCAAQsQM6BAgAEEM6AggAOggIABCXAxCDAToECAAQHjoGCAAQCBAe OgQIABAYUOi-A1jh8QNgr YDaABwAHgCgAH7BYgBvCySAQ4w LjE5LjEu Mi4xLjAuMZgBAKABAaoBC2d3cy13aXotaW1nwAEB\&sclient=img\&ei=p6nYX801Nu p5OUPvdWVuAw\&bih=553\&biw= 1280\#imgrc=cs0fzuNKLFyjFM

Segundo a Prefeitura, durante todo o ano, são realizadas operações de dragagem dos canais, limpeza e desobstrução de bocas de lobo, recuperação de galerias (BELEM, 2019a), obras de macrodrenagem (BELÉM, 2017; 2019b), além da coleta de resíduos sólidos. Apesar disto, situações calamitosas acontecem quando ocorrem, simultaneamente, eventos chuvosos intensos e maré alta (PONTE; LEÃO; BARROS; CUTRIM, 2014), tal como nos primeiros meses de 2020, conforme o alerta da Prefeitura, na seguinte nota:
A Prefeitura de Belém alerta a população sobre os riscos de alagamentos em Belém até o próximo dia 14 de março. Para reduzir os impactos e alertar a população sobre possíveis danos, a Prefeitura informa que está atuando no monitoramento das marés e na prevenção de acidentes ocasionados por enchentes. Agentes da Defesa Civil Municipal, da Secretaria Municipal de Saneamento (Sesan), da Superintendência Executiva de Mobilidade Urbana de Belém (SeMOB) e da Guarda 
Municipal de Belém (GMB) atuam de forma integrada em ações educativas e preventivas.

Os riscos de maré alta são considerados altos para índices a partir de 3 metros quando coincidentes com chuvas fortes e, altíssimos, para marés a partir de 3,5 metros (PORTAL DE BELÉM, 2020).

Contudo, tais situações não ocorrem tão somente por conta da coincidência desses fenômenos naturais. Estudos demonstram que essas ocorrências são consequentes, também, da falta de planejamento e da não utilização de soluções chamadas não estruturais (leis e regulamentos para a minimização dos riscos, planejamento para o desenvolvimento e uso de áreas sujeitas à inundação, sistemas de alerta de enchentes, zoneamento de áreas com risco de inundação), para enfrentar esses fenômenos (SANTOS; ROCHA, 2013; G1-PARÁ, 2019b).

\section{CONTROLE SOCIAL E CONSELHOS GESTORES}

A Lei no 11.445/2007 (BRASIL, 2007), chamada Lei Nacional do Saneamento (LNSB), em seu Art. $2^{\circ}$, inciso X, dispõe que o controle social é um dos princípios fundamentais, a partir dos quais os serviços públicos de saneamento básico devem ser prestados no país. Além disso, conceitua-o como sendo o:

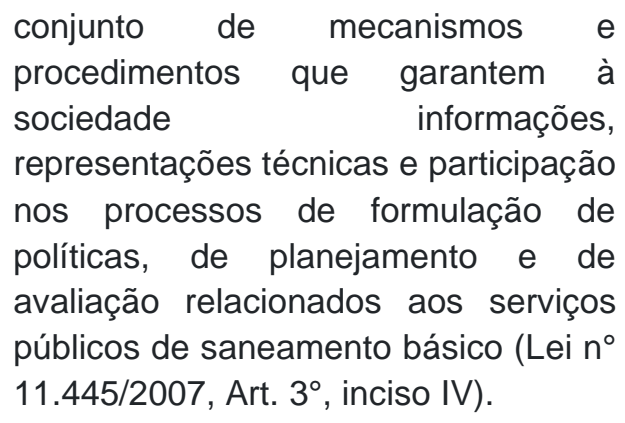

Para compreender melhor este conceito, Souza (2014) buscou subsídios nos estudos de Correia (2005), nos quais estão apresentadas as bases sociológicas que fundamentam o controle social a partir do aparato teórico-conceitual do filósofo italiano Antonio Gramsci. Para Correia (2005), o controle social:

envolve a capacidade que os movimentos sociais organizados na sociedade civil têm de interferir na gestão pública, orientando as ações do Estado e os gastos estatais na direção dos interesses da maioria da população (CORREIA, 2005, p. 59).

Sendo assim, trazendo esta compreensão sociológica para a área do saneamento básico, Souza (2014) propõe que o controle social seja definido como:

a capacidade de interferência da sociedade civil, perpassada pelos interesses antagônicos de usuários, catadores de resíduos, prestadores, gestores, empresários e políticos, na condução das ações do Estado, como a formulação de políticas, o planejamento, a prestação e a avaliação dos serviços públicos que o compõem (SOUZA, 2014, p. 25).

Em outras palavras, no dizer de Oliveira (2008), o controle social em saneamento básico é:

qualquer ação conjunta dos cidadãos para regular e fiscalizar os serviços de saneamento básico ofertados e para potencializar os seus efeitos sobre a saúde da população, bem como os benefícios socioambientais de interesse público, resultante de ações sanitárias implantadas (OLIVEIRA, 2008, p. 42).

Esse controle é, portanto, uma possibilidade, do ponto de vista das chamadas classes subalternas, assim designadas segundo propõe Gramsci, por estarem fora do poder e pelo lugar que ocupam nas relações de produção (SIMIONATTO, 2009; BRAVO; CORREIA, 2012). Trata-se, apenas, de possibilidade, pois esse controle depende da correlação de forças que, no espaço da sociedade civil, se estabelece na disputa contra a hegemonia conquistada pelo alcance do poder. Sendo assim, os conselhos gestores de políticas públicas, como mecanismos de controle social, "não são mecanismos acima da sociedade, nem são instâncias isoladas imunes aos conflitos de interesse, cooptação, disputas da direção da política social articuladas a projetos societários, mesmo que isto não esteja 
explicitado" (BRAVO; CORREIA, 2012, p.135).

Ao regulamentar a LNSB, o Decreto Federal $n^{\circ}$ 7.217/2010 (BRASIL, 2010), em seu Art. 34, incisos de I a IV, determina como mecanismos de controle social:

- debates e audiências públicas

- consultas públicas

- conferências das cidades;

- participação de órgãos colegiados de caráter consultivo na formulação da política de saneamento básico, bem como no seu planejamento e avaliação

Quanto às audiências e consultas públicas, o citado Decreto determina que o primeiro tipo de evento deve ser realizado de modo a possibilitar o acesso da população, podendo ocorrer de forma regionalizada. Quanto ao segundo tipo, deve ser promovido de forma a possibilitar que qualquer do povo, independentemente de interesse, ofereça críticas e sugestões a propostas do Poder Público, as quais deverão ser adequadamente respondidas.

Relativamente aos órgãos colegiados, estes são conselhos gestores de políticas públicas, neste caso a de saneamento, compostos por um colégio de conselheiros, representantes de diversos segmentos sociais e do Executivo. $O$ Decreto em tela determina que nos conselhos de saneamento, é assegurada a participação de representantes:

- dos titulares dos serviços

- de órgãos governamentais relacionados ao setor de saneamento básico

- dos prestadores de serviços públicos de saneamento básico

- dos usuários de serviços de saneamento básico

- de entidades técnicas, organizações da sociedade civil e de defesa do consumidor relacionadas ao setor de saneamento básico

$\mathrm{Na}$ área de saúde, por exemplo, metade de seus membros é composta por representantes dos usuários do Sistema Único de Saúde (SUS), sendo a outra metade dividida igualmente entre representantes do Executivo e dos profissionais de saúde.

Em atendimento ao que determina a citada Lei quanto à instituição, por meio de legislação específica, do controle social realizado por órgão colegiado, sob pena de impedimento ao acesso a recursos administrados pela União, foi criado, em Belém, em 2008, um Conselho Municipal de Água e Esgotos (BELÉM, 2008), cujo funcionamento somente ocorreu a partir de 2015. Este, portanto, somente atua no que diz respeito a estes dois componentes do saneamento básico.

No âmbito estadual, a Política Estadual de Saneamento Básico, instituída pela Lei $\mathrm{n}^{\circ}$ 7.731/2013, criou um Conselho Estadual de Saneamento (PARÁ, 2013) que controlaria o saneamento em sua totalidade de componentes. Este, contudo, até o momento, está inoperante. Além disso, analisando a modelagem que recebeu no contexto da Política em questão, Souza (2015) destaca que tal conselho não apresenta caráter deliberativo, não integra o Sistema de Saneamento do Estado, existindo apenas para dar cumprimento às diretrizes nacionais ditadas pela LNSB, sem qualquer atuação concreta, o que poderá redundar em prejuízo para a efetividade do controle pela sociedade.

\section{METODOLOGIA}

Este é um estudo descritivo (APOLINÁRIO, 2007), baseado em análise documental (GIL, 2002). Inicialmente, foram selecionados para o estudo os conselhos municipais de Saúde, de Meio Ambiente, de Desenvolvimento Urbano e das Cidades, do município de Belém. Contudo, considerando a extensão da problemática ligada aos resíduos sólidos em Belém, que envolve, também, os municípios de Ananindeua e Marituba, alterando os objetivos iniciais propostos para este estudo, os conselhos municipais de Saúde, de Meio Ambiente, de Desenvolvimento Urbano e das Cidades destes dois municípios, igualmente, foram incluídos na investigação, mas apenas na perspectiva do controle social sobre o manejo dos resíduos sólidos.

O contato entre os pesquisadores e esses 12 conselhos foi marcado por situações diversas, tal como sumariza o quadro 1.

Levando em conta o mesmo argumento da intermunicipalidade da problemática dos resíduos sólidos, também foram selecionados e contatados, todos com sucesso, os conselhos estaduais de Saúde, de Meio Ambiente e das Cidades, além do conselho de Recursos Hídricos, perfazendo, neste âmbito, um total de quatro 
conselhos.

Por conta das dificuldades de contato e da inexistência de alguns conselhos, como acima exposto, do total de 16 conselhos, somente 12 receberam ofícios do IFPA, entregues em mãos pelos pesquisadores, nos quais constava a solicitação de acesso aos documentos de interesse da pesquisa.

A verificação da presença dos temas de interesse do estudo, nas pautas das reuniões ocorridas no período de janeiro de 2017 a dezembro de 2018 (objetivo específico 1), foi realizada a partir de consulta às atas fornecidas pelos conselhos, concernentes às reuniões ocorridas no intervalo de tempo supracitado.

As atas que reportaram temas de interesse foram lidas minuciosamente na sua integralidade, para que fosse identificado seu conteúdo (o objetivo específico 2): tema tratado, posicionamentos assumidos pelos conselheiros, encaminhamentos definidos e decisões tomadas.

A leitura desse material também possibilitou identificar se nele havia registros da criação de resoluções do conselho, decorrentes das discussões havidas durante as reuniões.

Quadro 1: Situação dos Conselhos municipais quanto aos contatos realizados pelos pesquisadores

\begin{tabular}{|c|c|c|c|}
\hline \multicolumn{1}{|c|}{ CONSELHO } & BELÉM & ANANINDEUA & MARITUBA \\
\hline SAÚDE & contatado & contatado & contatado \\
\hline MEIO AMBIENTE & contatado & não contatado por ser \\
inexistente & $\begin{array}{c}\text { contatado, mas não } \\
\text { aceitou ofício }\end{array}$ \\
\hline URBSENVOLVIMENTO & $\begin{array}{c}\text { não contatado por ser } \\
\text { inexistente }\end{array}$ & $\begin{array}{c}\text { não contatado por falta } \\
\text { de localização do } \\
\text { endeço }\end{array}$ & $\begin{array}{c}\text { não contatado por ser } \\
\text { inexistente }\end{array}$ \\
\hline
\end{tabular}

Fonte: Autores (2019).

\section{RESULTADOS E DISCUSSÃO}

Relativamente ao objetivo específico 1, chama atenção a inexistência do Conselho das Cidades em Belém e em Marituba e do Conselho de Desenvolvimento Urbano em Ananindeua, como também se destaca a dificuldade encontrada para localizar o endereço do Conselho da Cidade, em Ananindeua. Trata-se de situações que comprometem o objetivo do controle social, pois limitam a participação da sociedade. A esse respeito, ficam no ar as perguntas: qual o motivo da inexistência dos conselhos? Será, mesmo, que existe o Conselho de Ananindeua?

Outra situação, ainda mais significativa, foi a recusa do Conselho de Desenvolvimento Urbano de Marituba, município que vivenciou em seu território toda a problemática em análise (COSTA; MOREIRA, 2018), em aceitar o ofício que os pesquisadores desejavam entregar. Após percorrer mais de um setor do órgão onde funciona o conselho, os pesquisadores foram informados de que não seriam atendidos, pois o órgão não tratava de controle social. Contudo, não foi apenas nesse conselho que se observou a dependência que se manifesta em relação à secretaria do Executivo que atua no seu campo de política.

Dentre os 12 conselhos que receberam o ofício, apenas seis, alguns após meses de espera, disponibilizaram suas atas para análise das pautas: os conselhos municipais de Saúde, Meio Ambiente, Desenvolvimento Urbano e os conselhos estaduais de Saúde, Meio Ambiente e Recursos Hídricos.

Merece destaque o posicionamento do Conselho Estadual de Cidades. Este não efetuou a entrega das atas, embora tenha agendado fazêlo, por mais de uma vez, inclusive com a informação de que estas continham dados relevantes para a pesquisa. Justificativas como a ausência da pessoa que dispunha da chave do armário onde as atas estavam guardadas foram apresentadas.

Em outras palavras, apenas $50 \%$ dos conselhos que receberam a solicitação de disponibilização de atas anuíram em fazê-lo. 
Fatos como este, que depõem contra os conselhos, no que tange a sua capacidade de organização e de franquear livre acesso dos cidadãos a seus registros, também foram identificados por Cunha (2007) e Souza e Heller (2019).

Do total de atas consultadas, nenhuma se referiu à drenagem de águas pluviais e apenas uma reportou-se à temática resíduos sólidos. Isto revela, em relação à primeira temática, a total omissão em tratá-la, ainda mais sendo ela de grande importância em uma cidade com os problemas evidenciados por Braga, Barbosa e Almeida (2014), Ponte (2015), Ponte, Leão, Barros e Cutrim (2014), Fragoso, Silva, Silva, Alves e Carvalho (2016), Cavalcante, Magalhães, Gomes e Carvalho (2017) e Costa, Bittencourt, Teixeira e Blanco (2016).

Nada a menos se pode dizer em relação à segunda temática, mesmo tendo sido objeto de discussão de um conselho, por ser merecedora de mais atenção, pela importância que tem, conforme reportam Pará $(2017 ; 2019)$ e Costa e Moreira (2018). A ata em questão, que abordou essa temática, registrou a $4^{\mathrm{a}}$ Reunião Ordinária de 2017 do Conselho Estadual de Saúde, ocorrida no dia 25 de abril daquele ano.

Quanto ao objetivo específico 2, uma das pautas da supracitada reunião tratou da situação logística do Aterro Sanitário de Marituba. A ata correspondente registra que os conselheiros discutiram a problemática ambiental local, decorrente da poluição causada pela CPTR.

Tal ata refere que o representante da comunidade do entorno do aterro e membro da comissão Fora Lixão, ao destacar a ocorrência de nove óbitos relacionados a problemas respiratórios e infecciosos na comunidade, por meio de vídeos, passou a apresentar breve levantamento histórico da situação do aterro, comparando com o que seria o projeto dessa obra, elaborado pela empresa responsável. Tal comparação, bastante pertinente, também foi objeto da análise de Costa e Moreira (2018) em seus estudos.

Por sua vez, o representante da SEMAS, convidado a se manifestar, afirmou que este órgão chegou a emitir 28 autos de infração e outras diversas notificações contra a empresa, em função do descumprimento de normas ambientais e de projeto, conforme já citado com base em Costa e Moreira (2018).
No que tange ao objetivo específico 3 , verificou-se que, diante da situação apresentada na citada reunião, os conselheiros sugeriram que - conselho criasse uma resolução específica sobre a temática, a fim de buscar minimizar os transtornos causados pelo lixão.

Identificou-se que a Resolução ํำ 22, então produzida, determinou que:

- as Empresas Revita e Guamá Resíduos Sólidos suspendessem temporariamente as suas atividades em Marituba, até que fossem por elas atendidas as adequações sanitárias exaradas em um Termo de Ajuste de Conduta, acordado com os prefeitos de Belém, Ananindeua e Marituba e o Governo do Estado do Pará, assim como as adequações das notificações dos órgãos Estadual $e$ Municipal de Meio Ambiente e Saúde Pública;

- a Secretaria de Estado de Saúde Pública do Pará (SESPA) fosse incluída, como membro, na comissão do Fórum Permanente Fora Lixão de Marituba para acompanhamento e deliberações de audiências;

- a SESPA e a SEMAS apresentassem Laudo Técnico da real situação do Aterro Sanitário de Marituba, elencando suas ações de monitoramento, produção de relatórios, emissão de notificação e lavratura de autos com as determinações e aplicação de multa por descumprimento;

- a SESPA fizesse um estudo de viabilidade quanto à ampliação do recurso financeiro da saúde à Secretaria Municipal de Saúde de Marituba, a fim de conter os problemas de saúde causados pelo Lixão;

- as Empresas Revita e Guamá Resíduos Sólidos fossem informadas que 0 Conselho Estadual de Saúde, no dia 26 de maio de 2017, de 08h00min às $12 \mathrm{~h} 00 \mathrm{~min}$, realizaria visita à CPTR para levantamento de informações para subsidiar suas deliberações sobre o caso;

- fosse encaminhada cópia da citada Resolução às Secretarias Municipais de Saúde de Marituba, Belém, Ananindeua, Benevides e Santa Barbara. 
Analisando estas determinações, observase lapso quanto ao nome de uma das empresas (Guamá Tratamento de Resíduos e não Guamá Resíduos Sólidos). Contudo, significativo, de fato, é não se ter informações quanto ao cumprimento/realização das medidas determinadas pelo conselho. Como Conselho de Saúde que é, sua natureza é deliberativa, então, paira no ar a pergunta: qual a efetividade da ação desse conselho sobre a temática em questão? Souza e Heller (2019), ao estudar a efetividade de conselhos de saúde e de saneamento, observaram falhas importantes, como esta em questão. Para os autores, mesmo com experiência mais larga, decorrente de seus anos de funcionamento, os conselhos de saúde por eles estudados não se mostraram mais efetivos que os neófitos conselhos de saneamento, pois dependiam da homologação de suas decisões pelo Executivo, o que nem sempre logravam obter. Assim, apresentaram baixa efetividade, tendo em vista os propósitos do controle social em saúde, dispostos pela legislação.

Há outro aspecto, contudo, a observar: a viabilidade técnica do que determina a Resolução, principalmente no que tange à suspensão das atividades da CPTR, pois, podese perguntar: em que local os resíduos passariam a ser dispostos? Novamente no lixão do Aurá? Teriam os conselheiros noção real dos impactos de tal deliberação para a saúde pública? Souza e Heller (2019), ao examinarem o grau de institucionalização dos conselhos que estudaram como variável interveniente para a efetividade dos mesmos, destacam a importância de órgãos internos, tais como comissões e câmaras técnicas, uma vez que esses órgãos contribuem para o esclarecimento dos conselheiros acerca de temas específicos que, muitas vezes, desconhecem.

\section{CONCLUSÃo}

Antes de abordar os resultados obtidos neste estudo, cabe ressaltar o problema da falta de observação do princípio fundamental da integralidade, que a Lei $\mathrm{n}^{\circ} \quad 11.445 / 2007$ estabeleceu para o saneamento, juntamente com o controle social, na política de saneamento de Belém. Ao criar um conselho de saneamento que controla apenas a política de abastecimento de água e de esgotamento sanitário, excluindo as temáticas em estudo neste trabalho, incorre-se em grave desrespeito à Lei, que não definiu o citado princípio por simples acaso.

Ao analisar os resultados obtidos, estes revelam, relativamente aos objetivos específicos propostos que:

1) nenhum conselho contatado teve pautas relacionadas ao serviço de manejo de águas pluviais em Belém, uma vez que este tema não foi tratado em nenhuma das atas consultadas; somente um conselho - o Conselho Estadual de Saúde - apresentou uma única pauta sobre o manejo de resíduos sólidos;

2) a pauta relativa ao manejo de resíduos sólidos (situação logística do Aterro Sanitário de Marituba) foi discutida no Conselho Estadual de Saúde, tendo sido abordada a problemática ambiental local, decorrente da poluição causada pelo lixão em que se transformou a CPTR, assim como seus impactos sobre a saúde dos moradores do entorno;

3) como consequência das discussões havidas no Conselho Estadual de Saúde, foi produzida a Resolução $n^{\circ}$ 22/2017, que define, dentre outros itens, a suspensão das atividades da CPTR; a assinatura de Termo de Ajuste de Conduta pelos prefeitos de Belém, Ananindeua e Marituba e o Governo do Estado do Pará; a inclusão da SESPA como membro da comissão do Fórum Permanente Fora Lixão de Marituba para acompanhamento e deliberações de audiências.

Dessa forma, o objetivo geral proposto foi, igualmente, alcançado, possibilitando concluir-se que a atuação dos conselhos estudados, no que tange ao manejo de resíduos sólidos e de águas pluviais, mostrou-se comprometida. Observou-se, também, que os conselhos são dependentes das secretarias municipais e estaduais que executam a política por eles controlada, não apresentando autonomia própria, o que dificulta as suas atividades.

Além disso, os conselhos dos três municípios em estudo apresentam dificuldades no que tange à relação com o público (sociedade) que almeja obter informações, uma vez que os processos de tramitação demoram meses, deixando documentos pendentes ou sem resposta. 


\section{REFERÊNCIAS}

APOLINÁRIO, F. Dicionário de metodologia

científica: um guia para a produção do conhecimento científico. São Paulo: Atlas; 2007.

BELÉM. Macrodrenagem resolverá os alagamentos. 2017. Disponível

em:http://www.agenciabelem.com.br/clipping/detalhes/1 23441. Acesso: 12 mar. 2020.

. Lei no 8.630/2008, de 07 fevereiro de 2008. Transforma o Serviço Autônomo de Água e Esgoto de Belém - SAAEB, criado pela Lei $n^{\circ} 6.695$, de 17 de junho de 1969, em Agência Reguladora Municipal de Água e Esgoto de Belém - AMAE/Belém, cria cargos efetivos e em comissão e dá outras providências. Belém, 2008.

\section{. Prefeitura intensifica ações de limpeza e} desobstrução de bueiros. 2019a. Disponível em:http://agenciabelem.com.br/Noticia/187449/prefeitur a-intensifica-acoes-de-limpeza-e-desobstrucao-debueiros. Acesso: 12 mar. 2020.

Macrodrenagem: um presente da PMB para os moradores de Belém. PMB. 2019b. Disponível em: http://www.belem.pa.gov.br/app/c2ms/v/?id=1\&conteud o=4069. Acesso: 12 mar. 2020.

. Bacias Hidrográficas. 2020. Disponível em: http://www.belem.pa.gov.br/app/c2ms/v/?id=18\&conteu do=4756. Acesso: 12 mar. 2020.

BRAGA, R.C; BARBOSA, A.L.C; ALMEIDA, L.S. Urbanização e áreas de alagamentos em Belém: estudo da bacia da Estrada Nova. In: CONGRESSO BRASILEIRO DE GEÓGRAFOS, 7., 2014, Vitória. Anais... Vitória-ES: Associação dos Geógrafos Brasileiros, 2014

BRASIL. Lei no 11.445/2007, de 05 de janeiro de 2007. Estabelece diretrizes nacionais para o saneamento básico e dá outras providências. Brasília, 2007.

Decreto no. 7.217/2010, de 21 de junho de 2010. Regulamenta a Lei $\mathrm{n} 011.445$, de 05 de janeiro de 2007, que estabelece diretrizes nacionais para o saneamento básico e dá outras providências. Brasília, 2010.

Ministério do Meio Ambiente. Controle de enchentes. 2019. Disponível em: https://www.mma.gov.br/concursos-e-premios/premiochico-

mendes/itemlist/category/index.php?option=com k2\&vi ew=item\&id=8046\&ltemid=1119. Acesso: 12 mar. 2020.
BRAVO, M.I.S; CORREIA, M.V.C. Desafios do controle social na atualidade. Serviço Social e Sociologia, v. 109, p. 126-150.2012.

CAVALCANTE, I.C.S; MAGALHÃES, C.H.C.; GOMES, A.B.B; CARVALHO, B.G.P. Avaliação da drenagem urbana no município de Belém/PA: estudo de caso do bairro de Nazaré. In: CONGRESSO INTERNACIONAL RESAG, 3., 2017, Belo Horizonte. Anais... Belo Horizonte-MG: Rede e Saneamento e Abastecimento de Água, 2017.

CORREIA, M.V.C. Desafios para o controle social: subsídios para capacitação de conselheiros de saúde. Rio de Janeiro: Editora FIOCRUZ, 2005.

COSTA, C.E.A.S; BITTENCOURT, G.M; TEIXEIRA, L.C.G.M; BLANCO, C.J.C. Revista Gestão e Sustentabilidade Ambiental, Florianópolis, v. 4, n. 2, p. 329-344. 2016.

COSTA, M.X; MOREIRA, S.O. Disposição final de resíduos sólidos urbanos: impactos socioambientais decorrentes do gerenciamento do aterro sanitário de Marituba-PA. Trabalho de Conclusão de Curso (Tecnologia em Saneamento Ambiental) - Instituto Federal de Educação, Ciência e Tecnologia, Belém, 2018.

CRUZ, C.C.C.S. Uso e ocupação do solo nas bacias hidrográficas da Região Metropolitana de Belém: uma análise urbanístico-ambiental. Dissertação (Mestrado em Arquitetura e Urbanismo) - Universidade Federal do Pará, Belém, 2018.

CUNHA E.S.M. A efetividade deliberativa dos conselhos municipais de saúde e da criança e do adolescente no nordeste. In: Avritzer, L. (Org.). A participação social no Nordeste. Belo Horizonte: Editora UFMG, 2007. p. 135-162.

DIAS, R.P; SILVA, M.F.; SILVA, F.M. Urbanização e qualidade de vida da população residente no bairro da Cremação, Belém-PA. 2014. Disponível em: http://www.cbg2014.agb.org.br/resources/anais/1/1403 579749 ARQUIVO TRABALHOCBG.pdf. Acesso: 13 mar.2020.

FRAGOSO, G.A; SILVA, F.P; SILVA, J.C.C; ALVES, A.F; CARVALHO, B.G.P. Diagnóstico do sistema de drenagem urbana da cidade de Belém, Pará: um análise dos principais bairros da cidade. In: XIV ENCONTRO NACIONAL DE ESTUDANTES DE ENGENHARIA AMBIENTAL, ENEEAmb, II Fórum Latino e I SBEA Centro-Oeste, 2016, Brasília. Anais... Brasília-DF: UnB, 2016. 
FREIRE, T.S.C. A gestão dos resíduos sólidos urbanos no município de Belém: uma análise do gerenciamento e da possibilidade de geração de renda através da reciclagem de resíduos

(1997/2010). Dissertação (Mestrado em Desenvolvimento Sustentável do Trópico Úmido) Núcleo de Altos Estudos Amazônicos, Universidade Federal do Pará, Belém, 2010.

G1-PARÁ. MP pede responsabilização por irregularidades no aterro de Marituba. Disponível em: http://g1.globo.com/pa/para/noticia/2017/03/mppede-responsabilizacao-por-irregularidades-no-aterrode-marituba.html. Acesso: 12 mar. 2020.

G1-PARÁ. Alagamentos em Belém não são causados só pela forte chuva e maré alta, diz especialista. Disponível em:

https://g1.globo.com/pa/para/noticia/2020/03/12/alagam entos-em-belem-nao-sao-causados-so-pela-fortechuva-e-mare-alta-diz-especialista-entenda.ghtml. Acesso: 13 mar. 2020.

GIL, A.C. Como elaborar projetos de pesquisa. São Paulo: Atlas, 2002.

LOBATO, C.C.S; TAVARES, L.C. Problemas causados pelo Lixão do Aurá. In: CONNEPI, 7., 2012, Palmas.

Anais Eletrônicos... Palmas: Instituto Federal do Rio Grande do Norte 2012. Disponível em: http://propi.ifto.edu.br/ocs/index.php/connepi/vii/paper/vi ewFile/4878/2385. Acesso: 12 mar. 2020.

MATOS, F.O.; MOURA, Q.L; CONDE, G.B; MORALES, G.P; BRASIL, E.C. Impactos ambientais decorrentes do aterro sanitário da Região Metropolitana de Belém-Pa: aplicação de ferramentas de melhoria ambiental. Caminhos de Geografia, Uberlândia, v. 12, n. 39, p. 297-305. 2011.

MORAES, D.; MANOEL FILHO. Contribuição das chuvas do período da tarde em Belém e possíveis relações com a normal climatológica. Revista

Brasileira de Climatologia, ano 14, v. 23. 2018. Disponível em:

https://revistas.ufpr.br/revistaabclima/article/view/58364 35876. Acesso: 13 mar. 2020.

O LIBERAL. Cremação: de quando se buscava soluções para o lixo. 2019. Disponível em: https://www.oliberal.com/crema\%C3\%A7\%C3\%A3o-dequando-se-buscava-solu\%C3\%A7\%C3\%B5es-para-olixo-1.53618. Acesso: 12 mar. 2020.

OLIVEIRA, M.T.C.S. Aspectos conceituais e metodológicos da participação e do controle social. In: Secretaria Nacional de Saneamento Ambiental (Org.). Elaboração de Plano Municipal de Saneamento Básico. Guia do profissional em treinamento: nível 2.
Salvador: ReCESA, 2008. p. 40-51. Disponível em: http://www.nurene.com.br/transversais/elaboracao de plano municipal de saneamneto basico.pdf. Acessado em: 05 jan. 2013.

OLIVEIRA, R.M.M. Gestão e gerenciamento de resíduos sólidos urbanos: o programa de coleta seletiva da Região Metropolitana de Belém - PA. Dissertação (Mestrado em Desenvolvimento e Meio Ambiente Urbano) - Universidade da Amazônia, Belém, 2012.

PARÁ. Lei no 7.731/2013, de 20 de setembro de 2013. Dispõe sobre a Política Estadual de Saneamento Básico. 2013.

PARÁ. Agência Pará. Justiça autoriza Estado a assumir administração do aterro de Marituba. 2017. Disponível em:

https://agenciapara.com.br/noticia/2328/. Acesso: 12 mar. 2020.

PARÁ. Tribunal de Justiça do Estado. Selado acordo sobre tratamento de lixo. 2018. Disponível em:

http://www.tjpa.jus.br/PortalExterno/imprensa/noticias/ln formes/959098-empresas-e-prefeituras-selam-acordopara-tratamento-do-lixo.xhtml. Acesso: 12 mar. 2020.

PINHEIRO, A.C.L; PONTE, J.P.X; VALENTE, A.M.; LIMA, A.M.; PINHEIRO, P.Q.F. Assentamentos precários na região metropolitana de Belém: baixadas e ocupações. In: Estudos de casos em metrópoles selecionadas. 2016. Disponível em: http://repositorio.ipea.gov.br/bitstream/11058/9614/1/As sentamentos\%20prec\%C3\%A1rios.pdf

PONTE, J.P.X. Belém do Pará: cidade e água. Cadernos Metrópole, São Paulo, v. 17, n. 33, p. 41 60. 2015.

; LEÃO, M.B.M.S; BARROS, N.S; CUTRIM, R.S. Urbanização e drenagem urbana: concepções divergentes na bacia da Estrada Nova, Belém-PA. In: SEMINÁRIO NACIONAL SOBRE O TRATAMENTO DE ÁREAS DE PRESERVAÇÃO PERMANENTE EM MEIO URBANO E RESTRIÇÕES AMBIENTAIS AO PARCELAMENTO DO SOLO, 3., 2014, Belém. Anais... Belém-PA, Universidade Federal do Pará, 2014.

PORTAL DE BELÉM. Prefeitura alerta para os riscos de maré alta em Belém. Disponível em: https://belem.com.br/noticia/1935/prefeitura-alerta-paraos-riscos-de-mare-alta-em-belem. Acesso: 12 mar. 2020.

SADECK, L. Zonas de risco a alagamentos em Belém. 2011. Disponível em: https://geotecnologias.wordpress.com/2011/02/15/zona 
s-de-risco-a-alagamento-em-belem/). Acesso: 12 mar.2020.

SANTOS, F.A.A; ROCHA, E.J.P. Alagamento e inundação em áreas urbanas. Estudo de caso: cidade de Belém. Revista GeoAmazônia, Belém, v. 02, n. 2, p. 33-55. 2013.

SIMIONATTO, I. Classes subalternas, lutas de classe e hegemonia: uma abordagem gramsciana. Rev.

Katálysis, v. 2, n. 1, p. 41-49, 2009.

SOARES, K.G. As formas de morar na Belém da belle-époque (1870-1910). Dissertação (Mestrado em História) - Universidade Federal do Pará, Belém, 2008.

SOARES, L.S; QUEIROZ, J.F; SANTOS, V.C.P. O tratamento de resíduos sólidos na Região Metropolitana de Belém. In: CONGRESSO SULAMERICANO DE RESÍDUOS SÓLIDOS E SUSTENTABIDADE, 1., 2018, Gramado. Anais... Gramado-RS: Instituto Brasileiro de Estudos Ambientais, 2018.

SOUSA, D.R.D. Alagamentos no centro comercial da campina, Belém-Pa: identificação das causas e suas implicações de acordo com a percepção dos comerciantes locais. Dissertação (Mestrado) - UFPA,
Belém, 2016. Disponível em:

http://repositorio.ufpa.br/jspui/bitstream/2011/9530/1/Di ssertacao AlagamentosCentroComercial.pdf. Acesso: 13 mar. 2020

SOUZA, C.M.N. Experiências de participação e controle social em saúde: uma contribuição ao saneamento básico. Projeto de pesquisa. Não publicado. 2014.

Participação dos cidadãos na gestão do saneamento básico no Pará. Novos Cadernos NAEA v. 18, n. 2, p. 261-274. 2015.

; HELLER, L. Efetividade deliberativa em conselhos municipais de saneamento e de saúde: um estudo em Belo Horizonte-MG e em Belém-PA.

Ciência \& Saúde Coletiva, v. 24, n.11. p. 4325-4334. 2019.

VASCONCELOS JÚNIOR, M.R; CORRÊA, R.S.S. Impactos socioambientais causados pelo aterro sanitário no município de Marituba/PA. In: SEMINÁRIO DE SERVIÇO SOCIAL, TRABALHO E POLÍTICAS SOCIAIS, 2., 2017, Florianópolis. Anais... Florianópolis-SC: Universidade Federal de Santa Catarina, 2017. 